\title{
Assimilation of altimeter data in the ECMWF ocean analysis system 3.
}

\author{
ARTHUR VIDARD *
}

Institut National de Recherche en Informatique et Automatique, Grenoble, France

$$
\text { Magdalena Balmaseda }
$$

European Centre for Medium-range Weather Forecast, Reading, UK

$$
\text { DAVID ANDERSON }
$$

European Centre for Medium-range Weather Forecast, Reading, UK

\footnotetext{
* Corresponding author address: Arthur Vidard, LJK, B.P. 53, 38041 Grenoble cedex 9, France. E-mail: vidard@inria.fr
} 


\begin{abstract}
The latest version of the ECMWF ocean analysis system was recently introduced into operational use. This not only provides initial conditions for the monthly and seasonal forecast systems but also creates a historical reanalysis. For the first time, altimeter data are used in the ECMWF operational ocean analysis. However, making good use of altimetric sea level information was not easy and several difficulties had to be overcome. Various strategies were tried and compared. Attempts to use mean sea level from gravimetric satellites were also tried but no satisfactory method of using this data was found. The altimetric data used show a marked rising trend which can not be directly represented in the model as the Boussinesq approximation is used. A strategy for dealing with the trend is given.

Results of Observing System Experiments (OSEs) with and without altimeter data are described and results compared to illustrate the benefits from using altimetry. Although the results are positive, further developments are needed to more fully utilise the data.
\end{abstract}




\section{Introduction}

ECMWF has been running an ocean analysis system routinely since 1997. Initially this was used to provide initial conditions for seasonal forecasting, but more recently, it has been used to provide initial conditions for monthly forecasting as well. A new ocean analysis system (denoted ORA-S3) has been implemented and one of its novelties is the assimilation of altimeter data. The ORA-S3 analysis is described in Balmaseda et al. 2008. The aim of this paper is to describe in more detail the use of altimeter data in ORA-S3 and to explain the choices for design of the altimeter part of ORA-S3.

The period of high quality altimetery dates from 1992, with the successive launches of ERS-1 (1991-1996), Topex/Poseidon (1992-2005) and ERS-2 (1995-...), GFO (1998-...) and more recently Jason 1 (2001-...) and Envisat (2002-...). During this time the ocean in situ observing network has also evolved significantly with the consolidation of the TAO/TRITON and PIRATA mooring arrays, and the development of the ARGO float array (McPhaden et al 1998, Gould 2005).

Although the assimilation of altimetry was tested at ECMWF in a research framework some time ago (Alves et al 1999, Segschneider et al 2000) it was not introduced into operational use because there were still some open issues. Firstly, altimeter information on its own is not enough to reconstruct the thermal and salinity fields but needs to be combined with in situ data. Combining altimeter and in situ is not straightforward, however, and the previously proposed approach exposed some problems (see section 2). Secondly, the altimeter actually measures sea level anomalies. The development of gravity missions such as GRACE give estimates of the geoid, and hence provide information about the mean dynamic topography as well as variability. The feasibility and the relevance of assimilating this information along with anomalies had to be evaluated. Thirdly, there is an observed rising trend in sea level. Most ocean general circulation models, including that used at ECMWF make the Boussinesq approximation and hence implicitly assume the total volume of the ocean to be constant, even though the mean temperature is rising. This leads to an inconsistency 
between the model and observed sea level which had to be carefully addressed.

The goal of this paper is to address these specific issues. Although the assimation method is based on an Optimal Interpolation, which will be replaced in the next analysis system, the problems addressed here are relevant for more advanced data assimilation schemes. In section 2 we briefly describe the ORA-S3 ocean analysis system discussing different ways in which temperature, salinity and altimeter data can be combined. In section 3 we investigate the impact of the use of different reference mean dynamic topographies. A way to deal with the (rising) trend in sea level is discussed in Section 4. Finally, some results are given in section 5 .

\section{The ECMWF Data assimilation system 3}

The ocean data assimilation system for ORA-S3 is based on the HOPE-OI scheme in which the first guess is obtained by forcing the HOPE (Hamburg Ocean Primitive Equations) ocean model with daily fluxes of momentum, heat, and fresh water, while the observations are assimilated using an Optimal Interpolation (OI) scheme. The horizontal resolution is $1^{\mathrm{o}} \times 1^{\mathrm{O}}$ with equatorial refinement, in which the meridional resolution is increased gradually towards the equator, where it is $0.3^{\circ}$ in the meridional direction. There are 29 levels in the vertical, with a typical vertical thickness of 10 meters in the upper ocean. The vertical mixing is based on Peters et al. 1998. The barotropic mode is solved explicitly as described in Anderson and Balmaseda (2005). For further details of the model and assimilation see Balmaseda 2004, Anderson and Balmaseda 2005 and Balmaseda et al 2008.

The first-guess is obtained by integrating the ocean model from one analysis time to the next, forced by ERA40/OPS fluxes (ERA40 fluxes from the period January 1959 to June 2002 and NWP operational analysis thereafter). The stresses may be biased weak in the equatorial Pacific (Uppala et al. 2005), but no correction is made to them. The fresh

water fluxes from ERA-40 (Precipitation minus Evaporation, denoted P-E) are known to be 
inaccurate. A better estimate of the fluxes obtained by 'correcting' the ERA-40 precipitation values (Troccoli and Kallberg 2004) is used.

\section{a. In situ data assimilation}

The assimilation system used in this work is the same as that in Vidard et al. 2007, which is essentially that used at ECMWF to provide ocean initial conditions for the seasonal forecast system ORA-S3 (Balmaseda et al., 2008), except that the bias correction is not active. The temperatures $(T)$ are assimilated through a univariate Optimum Interpolation scheme based on Smith et al. (1995), and described in Alves et al. (2004), updated in Balmaseda (2004) for the operational version S2 and Balmaseda et al. (2008) for ORA$\mathrm{S} 3^{1}$. Salinity is then adjusted to conserve water mass properties (Troccoli et al. (2002), hereafter TH). For ORA-S3 the scheme has been significantly modified to account for vertical correlations (in S2 the OI was done model level by model level) and to add isopycnal dependencies in the background error correlation matrix formulations ( Balmaseda et al 2008).

Salinity $(S)$ is assimilated through a second step of OI: an increment in salinity is calculated by comparing salinity observations with model salinity on the same isotherm instead of the same model level. Haines et al. (2006) show that increments calculated in this way can simply be added to the salinity increments already introduced during the temperature assimilation step, as the two salinity increments are entirely complementary and orthogonal. The in situ data analysis step itself can be summarised by :

$$
\left(\begin{array}{c}
T^{a} \\
S^{a}
\end{array}\right)=\left(\begin{array}{c}
T^{b} \\
S^{b}
\end{array}\right)+\left(\begin{array}{cc}
\mathbf{K}_{T} & 0 \\
T H\left(\mathbf{K}_{T}\right) & \mathbf{K}_{S}
\end{array}\right)\left(\begin{array}{c}
T^{o}-H_{T}\left(T^{b}\right) \\
S^{o}-H_{S}\left(S^{b}\right)
\end{array}\right)
$$

where $\mathbf{K}_{T}$ and $\mathbf{K}_{S}$ are the gain matrices of the Optimal Interpolation in $T$ and $S$ respectively.

\footnotetext{
${ }^{1} \mathrm{~S} 2$ is the previous analysis system used operationally from August 2001 to March 2007 and to create an ocean reanalysis from January 1987 to March 2007
} 
They are significantly different since $S$ is assimilated in $T$-space and $T$ is assimilated in $z$ space. Superscripts $a, b$, and $o$ stand for analysis, background and observation respectively.

Prior to the 1st of January 2004 the in situ data come from the ENACT/ENSEMBLES dataset (Ingleby and Huddleston, 2006); after this date they come from the real-time GTS data stream. The system includes a built-in quality control (basically background check and cross validation) and all the observations are given the same weight (see Vidard et al. 2007). For the sake of simplicity, the right hand side of the equation (1) will be denoted $O I\left(T^{b}, S^{b}, T^{o}, S^{o}\right)$ or $O I($.$) hereafter. The final step is to make geostrophic corrections to$ the velocity field based on the updated density fields as described in Burgers et al.(2002).

\section{b. Combining in situ and altimetry}

Altimeter information is only one contribution to the observing system; it needs to be combined with in situ data. In this section we propose three ways of combining altimetry and in situ data. All are based on Cooper and Haines (1996), hereafter called CH96, projecting the sea level anomaly observations on subsurface temperature and salinity fields by assuming that the displacement of the top surface is due to vertical displacement of the water column.

The altimeter information is given by maps of merged satellite products provided by Ssalto/Duacs and distributed by Aviso. Maps of Sea Level Anomaly (MSLA) for a merged product combining several satellites using optimal interpolation and accounting for Long Wavelength errors are produced twice a week (on Wednesday and on Saturday mornings) at

a resolution of $\frac{1}{3}^{\circ} \times \frac{1}{3}^{\circ}$ (Le Traon et al., 1998, Ducet et al., 2000). Once acquired, the maps are processed to smooth out the small scale features the model cannot represent, and then interpolated onto the model grid. Instead of assimilating the Sea Level Anomaly (SLA) directly in the OI framework, pseudo $T / S$ profiles are created using CH96. Differences between model and satellite-derived sea-level are fed into the CH96 scheme to produce increments in $T$ and $S,\left(\Delta T_{\text {alt }}, \Delta S_{\text {alt }}\right)$ obtained by displacing vertically the background profiles such that there are no changes in bottom pressure. 


$$
\left(\begin{array}{c}
\Delta T_{\text {alt }} \\
\Delta S_{\text {alt }}
\end{array}\right)=C H 96\left(T^{b}, S^{b}, \eta^{b}, \eta^{o}\right)
$$

where $T^{b}, S^{b}$ are background temperature and salinity and $\eta^{o}$ and $\eta^{b}$ are the observed and background dynamic topography (DT). A detailed explanation on how to obtain $\eta^{o}$ from the altimetric SLA is given in section 3. Analysed $T$ and $S$ are then computed from

$$
\begin{aligned}
& T_{\text {alt }}=T^{b}+\omega \Delta T_{\text {alt }} \\
& S_{\text {alt }}=S^{b}+\omega \Delta S_{\text {alt }}
\end{aligned}
$$

where $\omega$ is a weighting factor dependent on latitude:

$$
\omega=\min \left(\alpha, \beta[\cos (l a t)]^{\gamma}\right) .
$$

The latitude dependence is introduced so that altimetery is not used at high latitude where the stratification is weak. The parameters $\alpha, \beta$ and $\gamma$ are set to $0.3,1$ and 8 respectively in the experiments presented in this paper and in the operational analysis system ORA-S3.

CH96 is designed to correct displacements of the density structure that are caused by model errors or errors in the forcing field such as errors in the wind. It is not able to correct for steric sea level changes due to a rise of global temperature, for errors in the fresh water input (precipitation minus evaporation plus river runoff) or for errors in the model watermass characteristics. As noted earlier, the method is not easily applied where the vertical stratification is weak.

\section{1) Strategies for the combination of altimeter and in Situ Data}

In this section we consider three different ways to combine altimeter and in situ data. 
M1) Altimeter as pseudo $T$ observations.

This method is largely described in Segschneider et al. (2001). The CH96 scheme is used to convert SLA into increments in temperature and these are combined with the temperature of the background, following eqns and 2 and 3, to create pseudo observations. The observation vector is then augmented by these pseudo-observations and fed into the $O I$ :

$$
\left(\begin{array}{c}
T^{a} \\
S^{a}
\end{array}\right)=O I\left(T^{b}, S^{b},\left(\begin{array}{c}
T^{o} \\
T_{a l t}
\end{array}\right), S^{o}\right)
$$

As described in Segschneider et al.(2001), altimeter measurements that are close to in situ measurements (within a $2^{\circ}$ box around it) are not used, and $S_{\text {alt }}$ is discarded because the correction would be redundant with that coming from the TH scheme included in the $O I$ analysis of $T_{\text {alt }}$.

M2) Altimeter analysis as background for in situ assimilation.

In this method, the altimeter and in situ information are used sequentially. First, CH96 is used to convert SLAs into increments in temperature and salinity and these, combined with the model background fields, produce the first analysis $\left(T_{\text {alt }}, S_{\text {alt }}\right)$ via equations (2), (3) and (4)). This analysis is then used as background for the assimilation of in situ $T$ and $S$ via an OI:

$$
\left(\begin{array}{c}
T^{a} \\
S^{a}
\end{array}\right)=O I\left(T_{a l t}, S_{a l t}, T^{o}, S^{o}\right) .
$$

M3) In situ analysis as background for altimeter assimilation.

This is also a sequential approach, similar to M2, but the order is reversed. First the assimilation of in situ $T$ and $S$ is performed via an OI, to yield a temporary analyses $\left(\tilde{T}^{a}, \tilde{S}^{a}\right)$ 


$$
\left(\begin{array}{c}
\tilde{T}^{a} \\
\tilde{S}^{a}
\end{array}\right)=O I\left(T^{b}, S^{b}, T^{o}, S^{o}\right)
$$

The analyzed $\left(\tilde{T}^{a}, \tilde{S}^{a}\right)$ are then used as background for the assimilation of SLA using the CH96 scheme:

$$
\begin{aligned}
& T^{a}=\tilde{T}^{a}+\omega \Delta \tilde{T}_{a l t} \\
& S^{a}=\tilde{S}^{a}+\omega \Delta \tilde{S}_{a l t}
\end{aligned}
$$

2) Comparison of the three strategies For COMBining ALtimetry AND IN SITU DATA.

To test these different methods we ran three experiments from the 1st of January 2002 to the 31st of December 2003, assimilating both in situ $T$ and $S$, as well as altimetry. All three experiments start from the same initial conditions. Profile data are assimilated in the same way in all the experiments.

Fig 1 shows the mean departure of the analyses from the ENACT/ENSEMBLES temperature and salinity observations in the equatorial Pacific and the equatorial Atlantic for each of the three methods. This figure reveals that in all the regions the bias is largest using M1 whereas the biases in M2 and M3 are quite similar. The bias of M1 is typically twice as large as that of M2 or M3. In fact, the bias in M1 is larger than if only in-situ data were assimilated (not shown).

The poor performance of M1 can have several causes. The CH96 scheme relies on a good representation of water-mass properties in the background field. Unfortunately the background fields are themselves biased, and so the pseudo-obs derived from altimetry in 
M1 will be biased. To assimilate them with the same statistical assumptions as real in situ observations may lead to an increase in the bias in the analysis. Even in the absence of bias, M1 would still use the information suboptimally, since it precludes the altimeter and in-situ information being used simultaneously in the same place since the altimeter is thinned in the proximity of in-situ observations. Finally, although originally tested with the assimilation of SLA maps in Segschneider et al. (2000), M1 is probably more suitable for using along track data as the information contained in one pseudo observation is propagated to the surrounding grid points through the OI. This process has already been performed by the data provider and should not be repeated, as otherwise extra weight is given to the altimeter data.

There is a further drawback with M1 as it adds many pseudo-observations to the OI process and therefore increases substantially the computing cost. For these reasons we choose not to use M1. The M2 and M3 analyses are of equivalent quality in Fig 1 and also with respect to comparison with other data (e.g. TAO and OSCAR currents). However, M3 requires an additional step compared to M2 since $\tilde{\eta}^{a}$ of Eq.(9) needs to be derived after Eq.(8). To avoid this extra complexity we use M2.

\section{Mean Dynamic Topography}

Altimetry provides information about the Sea Surface Height (SSH) relative to a reference ellipsoid (see Fig.2). The ellipsoid has no particular physical significance; what is required are measurements relative to the earth geoid. The sea surface referenced to the earth geiod is

often called dynamic topography (DT), and its time average is the mean dynamic topography (MDT). Until recently, estimates of the geoid were too inaccurate to allow their use. To avoid the need for a geoid, altimeter measurements were (and still are) given as sea surface height anomalies, frequently referred to as sea level anomalies (SLA) relative to a long term Mean Sea Surface Height, (MSSH). For the altimeter product used in this paper, the MSSH is the 
average over the 7 year period 1993-2000.

The model has a free surface and so SSH is a model variable. In the model world, the geoid is a sphere, and so the MSSH and MDT are equivalent. To compare the altimeter sea level with the model, we need to know the MDT. The observed sea level measurements can then be compared with the model sea level. In the absence of a highly accurate observed MDT we use a model MDT (i.e. MSSH, see Fig 3 upper panel), add the observed altimetric anomalies to that and then compare with the model sea level. The so-called "model MDT" also contains observational information, since it is estimated from an ocean analysis where in situ $T$ and $S$ observations were assimilated (experiment $E \_T S$ hereafter), and it is the average over the seven years 1993-1999.

With the launch of the gravimetric satellite missions CHAMP and GRACE, the knowledge of the geoid has improved greatly, leading to more accurate estimates of the MDT such as those provided by Nasa (Tapley et al., 2003, hereafter Tap03) or by CLS Space Oceanography Division (Rio and Hernandez, 2004, hereafter Rio5). The latter additionally uses in situ hydrologic and drifter data. However, these two products are only defined up to an arbitrary constant. The accuracy of the MDT is expected to improve further following the launch of the GOCE mission. The existence of an observation-based MDT would allow correction of errors in the mean state of the model. If the MDT is obtained from the model, only temporal and spatial variability contained in the altimetric anomalies is assimilated.

Different MDTs can differ by an arbitrary constant. For instance, over the area it covers (the very high latitudes are not present), the spatial mean of the Rio5 MDT is $1.35 \mathrm{~m}$ higher than the corresponding model MDT (or MSSH). These references being arbitrary, it should only be a matter of adding a given offset once and for all. Choosing the offset correction to be such that the spatial mean is the same for the model MDT and the observed MDT is probably not a good idea since there are very large differences in some places which may well be due to model errors. Including these in the spatial mean would lead to a degradation in some regions. If these regions of degradation were of particular importance such as the west 
Pacific for seasonal forecasting then nothing would have been gained; in fact the net effect of using the 'observed' MDT would be detrimental. However, looking at spatial structure of the differences between the two MDTs (Fig.4) it is clear that there is no unique way to determine the offset. The Rio5 MDT is higher than the model MDT in the Atlantic but is lower in the Pacific. If we wanted to reduce the difference in the Pacific, it would lead to an increase in the Atlantic. There is no simple way to assess the right balance, and being even a few centimeters wrong could have substantial impact on subsurface temperature and salinity. Moreover comparing Tap03 with Rio5 (see Fig.4) shows that the uncertainties in these products are not negligible even if they may be smaller than the differences with the model MDT.

To illustrate the sensitivity of the choice of MDT on the assimilation of altimeter data, we ran four experiments spanning the 10-year period 1 Jan 1993- 31 Dec 2002. First an analysis of in situ $T$ and $S$ observations only (hereafter $E_{-} T S$ ), is used to compute the model MDT $\left(M D T^{b}\right)$, and will also be used as a reference experiment. Experiment E_TSAM assimilates $T, S$ (as $E \_T S$ ) as well as altimeter data using $M D T^{b}$ from experiment E_TS. Two other experiments similar to $E_{-} T S A_{M}$ but using the MDTs from Rio5 and Tap03, called respectively $E_{-} T S A_{R}$ and $E_{-} T S A_{N}$ were also carried out. The two observation-based MDTs were adjusted to have the same spatial mean as the $M D T^{b}$ over the area they cover. In all the experiments the different data streams are assimilated sequentially using method M2.

The evolution of temperature and salinity averaged over the upper 300m (T300 and S300 respectively) is shown in fig 5 for the four experiments. Substantial modifications to T300 are apparent from the first months of the integrations. The experiments using external MDTs show, in the Tropical Pacific, a systematic decrease in T300 during the first year, consistent with the lower value of MDT used in Rio5 and Tap03 compared to the model MDT. The amplitude of the temperature change $(0.3 K)$ is comparable to the magnitude of the interannual variability in the tropical Pacific. The values of S300 in the experiments 
with external MDTs are higher than those for $E_{-} T S$ and $E_{-} T S A_{M}$ though the changes in S300 are not so sudden as for T300. Comparisons with profile data (Fig. 6) shows that the impact of the external MDTs in the subsurface $T$ and $S$ are frequently detrimental. Different choices of the offset will give different results. Moreover for long reanalyses, such as from 1959 up to present, the kind of abrupt jump in $\mathrm{T}$ in 1993 shown in fig 5 when using either of the observed MDT's is neither acceptable nor realistic. See Balmaseda et al 2007a for a description of results from the long reanalysis ORA-S3.

The above illustrates that it is not easy to use an observation-based MDT in a simple way and a more sophisticated scheme is needed including some bias-correction type algorithm (Vidard 2002, Drecourt et al.2006, Balmaseda et al.2007b). Alternatively (or additionally) one could try to assimilate the MDT differences during the pre-altimeter period. Using the MDT throughout the analysis period would avoid the jump in 1992, at the cost of a transition at the start of the reanalysis. However, we can not be sure that the MDT really is constant over prolonged periods such as the fifty years for which it is now possible to carry out ocean reanalyses.

Other groups have apparently successfully used an observation-based MDT, but they use other ocean configurations and in a limited domain, so avoiding the Pacific/Atlantic mismatch issue. "Spurious" temporal varibility as a consequence of the abrupt jumps resulting from the use of external MDT information is not such a problem if there is no need for a continuous historical reanalysis, but mainly an estimation of the current ocean state. In a higher resolution, North Atlantic system, Birol et al.(2005) showed that using a GRACEderived MDT may locally improve the representation of current velocities but at the expense of a less accurate temperature field. Castruccio et al.(2006), using a lower resolution system, appeared to find a beneficial impact from using GRACE data. However, although the model used was global they only used the GRACE-referenced MDT in the tropical Pacific, suggesting that they too had difficulty in using a global field. Further, the improvement was relative to a MDT obtained from the model, not using any in situ data. The model MDT 
used in this study is obtained from an analysis assimilating all in situ data and therefore likelt to be of higher quality than that from an experiment in which in situ data are not used. The MDTs can differ substantially, as can be seen in figure 3b but in any event, that from $E_{T} S$ will be closest to the model background. Eventually we decided to continue using a model-derived MDT, recognising that in so doing we loose the extra-information about the mean circulation potentially contained in an observation-based MDT.

\section{Trends in the global mean sea level}

Altimetry shows a rise in sea level over the last few years: see for example Balmaseda et al 2007a, and figure 7, which shows the time series of the global sea level from the altimeter data, for the period 1993-2006. The trend in global sea level dominates the variability. If not treated correctly, the trend in sea level can be a problem when assimilating altimeter data in a Boussinesq model. In ORA-S3, the global sea level trend is removed by substracting the global sea level $\bar{\eta}$ from the altimeter sea level maps before they are assimilated via the CH96 scheme. This is discussed in more detail below.

On the other hand there is an open debate about the attribution of sea level trend: how much is due to thermal expansion (steric) and how much is due to mass change over the ocean (Church and White 2006, Balmaseda et al 2007a). In principle, ocean reanalyses can help to answer this question, since they use all possible information: by combining model first guess with subsurface data it should be possible to reduce the error in the estimation of the steric height $\eta_{s}$. By comparing the total trend in sea level given by the altimeter data with the trend in steric height given by the ocean analysis, it is possible to estimate the component of the trend due to mass variations. In ORA-S3 the information given by the altimeter data about changes in the global mean sea level $(\bar{\Delta} \eta)$ is compared every assimilation cycle with 
the changes in ocean analysis steric height $\left(\bar{\Delta}_{s}\right)$. The residual $\left(\Delta \bar{\eta}_{m}\right)$ where

$$
\bar{\nu}_{m}=\overline{\Delta \eta}-\bar{\Delta}_{s}
$$

is applied as a fresh water flux uniform in space. The partition between volume change and mass change is quite valuable information, since it can help to close the fresh water budget over the oceans, which is currently a problem in ocean analysis.

To further assess the effect of sea level rise on the analysis system, we conducted additional experiments assimilating altimetry and in situ data and using a model derived MDT. The experiments differ in the way the trend is handled. The different experimental strategies are described below. Let us consider first $E_{-} T S A_{d} T r$ in table $2^{2}$ and split the various steps as follows: step 1) add MDT to map of sea level anomaly from CLS, to create $\eta^{o}$ step 2) average this quantity over the domain of altimeter data, and remove it from the sea level calculated in step 1, step 3) average the background DT $\left(\eta^{b}\right)$ over the model domain and and remove it from $\eta^{b}$, step 4) compare the detrended altimeter sea-level with model sea level, step 5) assimilate the altimeter spatial variations, step 6) add back the mean sea level difference, averaged over the model domain, step 7) adjust the sea surface salinity.

Step 7 requires some additional calculations. The altimeter trend can arise partly as a result of steric effects (warm water expanding) and partly as a result of increased mass (PE $+\mathrm{R}$ not integrating to zero, perhaps as a result of inaccurate measurements or as a result of ice over Greenland or Antartica melting). The altimeter can not make this distinction but we can calculate the steric effect from the ocean analysis. The steric effect is subtracted from the altimetric trend and the difference is assumed to be fresh water input. In the absence of any better strategy, this is distributed uniformly over the model domain.

In experiments E_TS $A_{r}$ and $E_{-} T S A_{d}$ step (6) above is omitted, and P-E+R is adjusted to keep a constant global sea level. In experiment $E_{-} T S A_{d}$, the altimeter data were detrended before they were used but no a posteriori correction to the trend was made, in contrast to

\footnotetext{
${ }^{2} E_{-} T S A_{d} T r$ is the same as experiment $E_{-} T S A_{M}$ in table 1
} 
experiment $E \_T S A_{d} T r$. In experiment $E \_T S A_{r}$ the altimeter sea level is not detrended prior to assimilation (i.e., step (2 and 3) above are omitted). Results from these experiments are shown in figs 8 and 9.

Until the recent development of the Argo network, the South Pacific was poorly observed and therefore the assimilation of altimeter data is likely to have a significant impact on southern ocean analyses. Fig.8 shows the evolution of SLA over the South Pacific for the three experiments; observations from Ssalto-Duacs are additionally shown in black. On this plot we can distinguish the experiment which has the global trend added a posteriori $\left(E_{-} T S A_{d} T r\right)$ from those that do not $\left(E_{-} T S A_{d}\right.$ and $\left.E_{-} T S A_{r}\right)$. This is largely as expected but it is not entirely obvious as the altimeter is given relatively low weight in the band $30 \mathrm{~S}$ to $60 \mathrm{~S}$.

Accounting for the trend in sea level also helps to improve the variability. The time correlation with observed SLA in this area for E_TS is 0.55. Assimilating the altimetry $\left(E_{-} T S A_{r}\right)$ without taking care of the global trend in sea level brings very little improvement (0.6 correlation) whereas accounting for the trend in sea level improves the correlation substantially to 0.95 for $E_{-} T S A_{d} T r$.

Whereas experiments $E_{-} T S A_{r}$ and $E_{-} T S A_{d}$ are very similar in terms of the sea level, this is not true in terms of heat content. Fig 8 shows $\mathrm{T}$ averaged over the upper $300 \mathrm{~m}$ of the global ocean for the three experiments. Experiment E_TSA shows a trend in heat content. Since the sea level trend has not been removed prior to assimilating the altimeter data, the CH96 scheme will try to raise the sea level by warming. On the other hand, the two experiments in which the trend has been removed a priori are very similar. Whether the trend is added a posteriori or not makes little difference to the heat content, though it does make a difference to the sea level as fig 7 shows. Based on these experiments we decided to detrend the altimeter data before assimilation and to add back the trend a posteriori as in experiment E_TSA $T r$. 


\section{Assessing the impact of the assimilation of altimetry on the quality of the analyses}

As a summary of the previous sections, the whole assimilation process can be described as a sequence of corrections, as illustrated below:

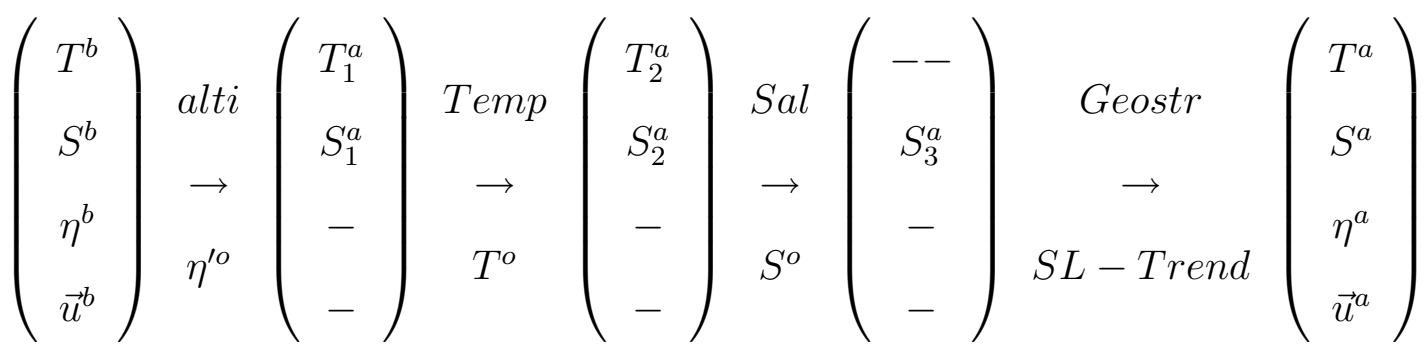

To evaluate the benefit of assimilating the altimeter data we compare three experiments from the same initial conditions and with the same ocean settings; the differences are in the data assimilated. The experiments are: Control, a forced ocean run with no data assimilation, E_TS where in situ $\mathrm{T}$ and $\mathrm{S}$ data are assimilated and $E_{-} T S A_{d} T r$ where additionally altimeter data are assimilated using the scheme in eqn(13).

Fig.8 shows that assimilating altimetry allows a better representation of sea level $\left(E \_T S A_{d} T r\right)$. This result could be expected, but one should remember that we are not assimilating SLA directly; rather we derive corrections to $\mathrm{T}$ and $\mathrm{S}$ from sea level. Moreover, by using M2 of section $\mathrm{b}$ we perform the OI of in situ $\mathrm{T}$ and $\mathrm{S}$ after the altimetry analysis and so there is no guarantee that this would not damage the sea level representation.

Fig.10 shows the mean Analysis minus Observation for the Niño 4 and Tropical Atlantic regions for the period 1993-2003 for $\mathrm{T}$ and $\mathrm{S}$ for the three experiments. In general there is a noticeable impact of assimilation of altimeter data: the difference with observation of both salinity and temperature is significantly reduced compared to the control. The fact that the assimilation of altimetry improves the fit to the in situ data is a positive result.

The Ocean Surface Current Analysis (OSCAR) project provides analyses of oceanic surface currents derived from satellite altimeter and scatterometer data (Bonjean and Lagerloef, 
2002). They are available from the end of 1992 up to near real-time and now cover the whole ocean from $60^{\circ} \mathrm{S}$ to $60^{\circ} \mathrm{N}$. Comparisons between OSCAR and the data from the World Wide Drifter Buoy Deployment, and between OSCAR and the TAO/TRITON/PIRATA mooring data shows that OSCAR products are of good quality especially in the tropical areas. (http://www.esr.org/\%7Ebonjean/oscar/global_validation/)

Fig 11 shows the correlation between the zonal component of the surface velocities from OSCAR monthly means and control (i.e. no data assimilation), E_TS and E_TSA $T r$ respectively for the period 1993-2005. Note the nonlinear colourscale in which white areas means correlation below 0.5. OSCAR data are not available along the coasts. In general, assimilation of in situ data improves the representation of surface currents, mainly in the tropical band (compare top to middle). A more significant and consistent improvement comes from the assimilation of SLA (bottom). However in some mid-latitude areas (Gulf-Stream and Kuroshio regions, and the southern oceans) the correlation with OSCAR remains below 0.5 .

OSCAR currents are not completely independent from sea level data, however, as altimetry is used in their construction. However, as we do not use SLA data directly but derive anomalies in $\mathrm{T}$ and $\mathrm{S}$ from them, there is no guarantee that this will lead to improved velocities. Therefore OSCAR currents are a good metric to assess the quality of our analysis.

The TAO array (McPhaden et al., 1998) measures current velocities in the upper 250$300 \mathrm{~m}$. These are truly independent data as we do not assimilate them, but, unfortunately, they are only available on a few moorings, mainly along the equator. Nevertheless we can compare our analysis to the available data. Fig.12 shows the correlation and the RMS differences between the TAO currents and the three simulations Control (blue), E_TS (black), E_TSA $A_{d} \operatorname{Tr}$ (red), at $170^{\circ} \mathrm{W}$ (top) and $156^{\circ} \mathrm{E}$ (bottom). The effect of the assimilation of altimetry is not very large but does show a positive improvement compared to $E \_T S$ on the upper part of the water column (upper 50-100m) though the effect is pretty much neutral on the lower part of the profiles. More in-depth diagnostics can be found in Balmaseda 
et al. 2008

\section{Conclusions}

In this paper we have presented results of various experiments we performed to guide our choices when designing the assimilation of altimeter into our ocean data assimilation system.

Three aspects of altimeter data assimilation were investigated. First we discussed assimilating both altimeter and in situ profile data and compared three different two-step methods. The method that was previously considered (Segschneider et al 2001) was found not to be adequate for the assimilation of altimeter maps.

Second, the impact of using different mean dynamic topographies (MDTs) to estimate the total sea level from anomalies was investigated. Due to the lack of a common and strict reference, it proved difficult to adjust the global spatial mean of the external products to our system. This is an important matter because errors in a global mean can lead to severe deterioration of the subsurface water characteristics and discontinuities in the analysis. It was shown that, at least in our system but is probably generally true that this is a complicated matter and needs sophisticated methods to deal with it.

Thirdly we considered trends and how to deal with them. The Boussinesq approximation is commonly made in ocean models. However they cannot represent the steric effect that is present in the altimeter measurements. In $\mathrm{S} 2$, in order to prevent the sea level from drifting too much as a result of the uncertainties in the water budget, the total volume of the global ocean was constrained to be constant. Therefore neither of the components of the observed sea level rise (thermal expansion and fresh water flux) could be represented in the model, leading to inconsistencies when comparing with the data. It is therefore crucial to treat separately the rising trend when assimilating sea level data, either by removing it altogether or by assimilating it separately.

Finally we showed that assimilating altimeter along with in situ profile data improved 
significantly the quality of the analyses, especially the surface currents.

\section{Acknowledgments}

We are indebted to the OSCAR project office for making the surface velocity data available to us. 


\section{REFERENCES}

Alves, O., D. Anderson, and K. Haines, 2001: Sea level assimilation experiments in the tropical pacific. J Phys Ocean, 31, 305-323.

Anderson, D. L. T. and M. Balmaseda, 2005: Overview of ocean models at ecmwf. Seminar on Recent developments in numerical methods for atmospheric and ocean modelling, ECMWF Seminar Proceedings, 103-111.

Balmaseda, A. V., M. and D. Anderson, 2008: The ecmwf ocean analysis system ora-s3. Mon. Wea. Rev.

Balmaseda, M., 2004: Ocean data assimilation for seasonal forecasts. Seminar on Recent developments in data assimilation for atmosphere and ocean, ECMWF Seminar Proceedings, $301-326$.

Balmaseda, M., 2005: Ocean analysis at ecmwf: from real-time ocean initial conditions to historical ocean reanalysis. ECMWF Newsletter, Autumn Issue (105).

Balmaseda, M., D. Dee, A. Vidard, and D. Anderson, 2007b: A multivariate treatment of bias for sequential data assimilation: Application to the tropical oceans. Q. J. R. Meteorol. Soc., 133, 167-179.

Balmaseda, M., A. Vidard, and D. Anderson, 2007a: Climate variability from the new system 3 ocean analysis. ECMWF Newsletter, Autumn Issue, 113.

Birol, F., J.-M. Brankart, J. Lemoine, P. Brasseur, and J. Verron, 2004: Assimilation of satellite altimetry referenced to the new grace geoid estimate. Geophys. Res. Letters, 32 (L06601), doi:10.1029/2004GL021329. 
Bonjean, F. and G. Lagerloef, 2002: Diagnostic model and analysis of the surface currents in the tropical pacific ocean. Journal of Physical Oceanography, 32 (10), 2938-2954.

Castruccio, F., J. Verron, L. Gourdeau, J. M. Brankart, and P. Brasseur, 2006: On the role of the grace mission in the joint assimilation of altimetric and tao data in a tropical pacific ocean model. Geophys. Res. Lett., 33 (L14616), doi:10.1029/2006GL025823.

Church, J. and N. White, 2006: A 20th century acceleration in global sea level rise. Geophys. Res. Lett., 33 (L01602), doi:10.1029/2005GL024826.

Cooper, M. and K. Haines, 1996: Data assimilation with water property conservation. J. Geophys. Res, 101 (C1), 1059-1077.

De Mey, P. and M. Benkiran, 2002: Ocean Forecasting, Conceptual basis and applications, chap. A multivariate reduced-order optimal interpolation method and its application to the Mediterranean basin-scale circulation, 472pp. N. Pinardi and J.D. Woods eds, SpringerVerlag, Berlin.

Drécourt, J., K. Haines, and M. Martin, 2006: Use of bias aware data assimilation to improve the gocina mean dynamic topography. Proceedings of the GOCINA international workshop, Luxembourg.

Ducet, N., P.-Y. Le Traon, and G. Reverdin, 2000: Global high resolution mapping of ocean circulation from topex/poseidon and ers-1 and -2. J. Geophys. Res., 105, 19 477-19498.

Gould, J., 2005: From swallow floats to argo the development of neutrally buoyant floats. Deep-Sea Research II, 52/3-4, 529-543.

Haines, K., J. Blower, J.-P. Drecourt, C. Liu, A. Vidard, I. Astin, and X. Zhou, 2006: Salinity assimilation using $s(t)$ relationships. Mon. Wea. Rev, 134 (3), 759-771.

Ingleby, B. and M. Huddleston, 2006: Quality control of ocean temperature and salinity profiles - historical and real-time data. J. Mar. Sys., 65, 158-175. 
Le Traon, P.-Y., F. Nadal, and N. Ducet, 1998: An improved mapping method of multisatellite altimeter data. J. Atmos. Oceanic Technol., 15, 522-534.

McPhaden, M. J., et al., 1998: The tropical ocean-global atmosphere observing system: A decade of progress. J. Geophys. Res., 103, 14169-14240.

Peters, H., M. C. Gregg, and J. M. Toole, 1988: On the parameterization of equatorial turbulence. J. Geophys. Res., 93, 1199-1218.

Rio, M.-H. and F. Hernandez, 2004: A mean dynamic topography computed over the world ocean from altimetry, in-situ measurements and a geoid model. Journal of Geophysical Research, 109 (C12032).

Segschneider, J., D. Anderson, and T. Stockdale, 2000: Towards the use of altimetry for operational seasonal forecasting. J of Climate, 13, 3115-3138.

Segschneider, J., D. Anderson, J. Vialard, M. Balmaseda, T. Stockdale, A. Troccoli, and K. Haines, 2001: Initialisation of seasonal forecasts assimilating sea level and temperature observations. J of Climate, 14, 4292-4307.

Smith, N., J. Blomley, and G. Meyers, 1991: A univariate statistical interpolation scheme for subsurface thermal analyses in the tropical oceans. Prog in Oceanography, 28, 219-256.

Tapley, B., D. Chambers, S. Bettadpur, and J. Ries, 2003: Large scale ocean circulation from the grace ggm01 geoid. Geophys. Res. Letters, 30.

Troccoli, A. and P. Kallberg, 2004: Precipitation correction in the era-40 reanalysis. Tech. Rep. 13, ECMWF, ERA-40 Project Report Series.

Troccoli, A., et al., 2002: Salinity adjustments in the presence of temperature data assimilation. Mon. Wea. Rev., 130, 89-102.

Uppala, S. and coauthors, 2005: The era-40 reanalysis. Q. J. R. Meteorol. Soc., 131,Part B, 2961-3012. 
Vidard, A., 2001: Toward the correction of model error in 4d variational data assimilation. application to a realistic ocean model. Ph.D. thesis, Université Joseph Fourier (Grenoble I), 196p, In French.

Vidard, A., D. Anderson, and M. Balmaseda, 2007: Impact of ocean observation systems on ocean analysis and seasonal forecasts. Mon. Wea. Rev., 135, 409-429, doi:10.1175/ MWR3310.1.

Wolff, J., E. Maier-Reimer, and S. Legutke, 1997: The hamburg ocean primitive equation model. Tech. Rep. 13, Deutsches Klimarechenzentrum, Hamburg. 


\section{List of Figures}

1 Mean Analysis minus Observation over the equatorial Atlantic (left) and equatorial Pacific (right) for temperature (top) and salinity (bottom) for the three methods M1 (black), M2 (grey) and M3 (dotted). Averaging period is 20022003. . . . . . . . . . . . . . . . . . . 25

2 Decomposition of Sea Surface Height . . . . . . . . . . . . . . . . 26

3 Upper) MDT derived from 7 years of experiment E_TS (1993-1999); Lower) Difference in MDTs between E_TS and Control (no assimilation) for the same period. Units are metres. . . . . . . . . . . . . . . . . Upper) Differences in Mean Dynamic Topography between Rio5 and an estimate from the ocean analysis from E_TS. Middle) Differences in Mean Dynamic Topography between Tap03 and an estimate from the ocean analysis from E_TS. Lower) Differences between Rio5 and Tap03. The global spatial average has been set to 0 for all fields. . . . . . . . . . . . .

5 Time series of temperatures (left) and salinity (right) averaged over the tropical Pacific ([30S, 30N]) and the first 300 meters of the expriments E_TSAM (dotted), E_TSAN (grey), E_TSA $A_{R}$ (dashed) and E_TS (black). . . . . . . .

6 Mean Analysis minus observation in the Nino3 [5S, 5N][210E, 270E], Tropical Atlantic[20N, 30N] and Equatorial Indian [5S, 5N], for temperature (top) and Salinity (bottom) of the expriments $E_{-} T S A_{M}$ (dashed gray), E_TS $A_{N}$ (dashed black), E_TSAR (grey) and $E_{-} T S$ (black). . . . . . . . . . .

7 Time series of the global sea level from altimeter data. Units are metres. From Balmaseda et al 2008. . . . . . . . . . . . . . . . . . . . . . 31

8 Time-series of sea-level in the South Pacific for experiments E_TS $A_{d}, E \_T S A_{r}$ and $E-T S A_{d} T r \ldots \ldots \ldots \ldots \ldots \ldots \ldots$

9 Time-series of the global average of temperature over the first $300 \mathrm{~m}$ for ex-

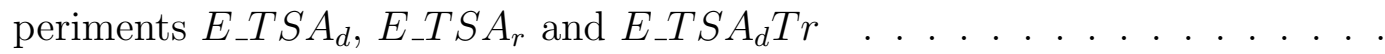

10 Mean Analysis minus Observation averaged over the NINO4 (top) and Tropical Atlantic (bottom) regions for temperature (left) and salinity (right)for Control(grey), E_TS (black) and E_TSA $\operatorname{Tr}$ (dashed grey) . . . . . . . . . . 34

11 Correlations with Oscar zonal component of the surface currents for Control(top), E_TS (middle) and E_TSA $T$ Tr (bottom) . . . . . . . . . . . . . 35

12 Correlation (left) and RMS differences (right) with TAO currents at the equator at $170^{\circ} \mathrm{W}$ (top) and $156^{\circ} \mathrm{E}$ (bottom), for experiments Control, E_TS and $E_{-} T S A_{d} T r \ldots \ldots \ldots \ldots \ldots$ 

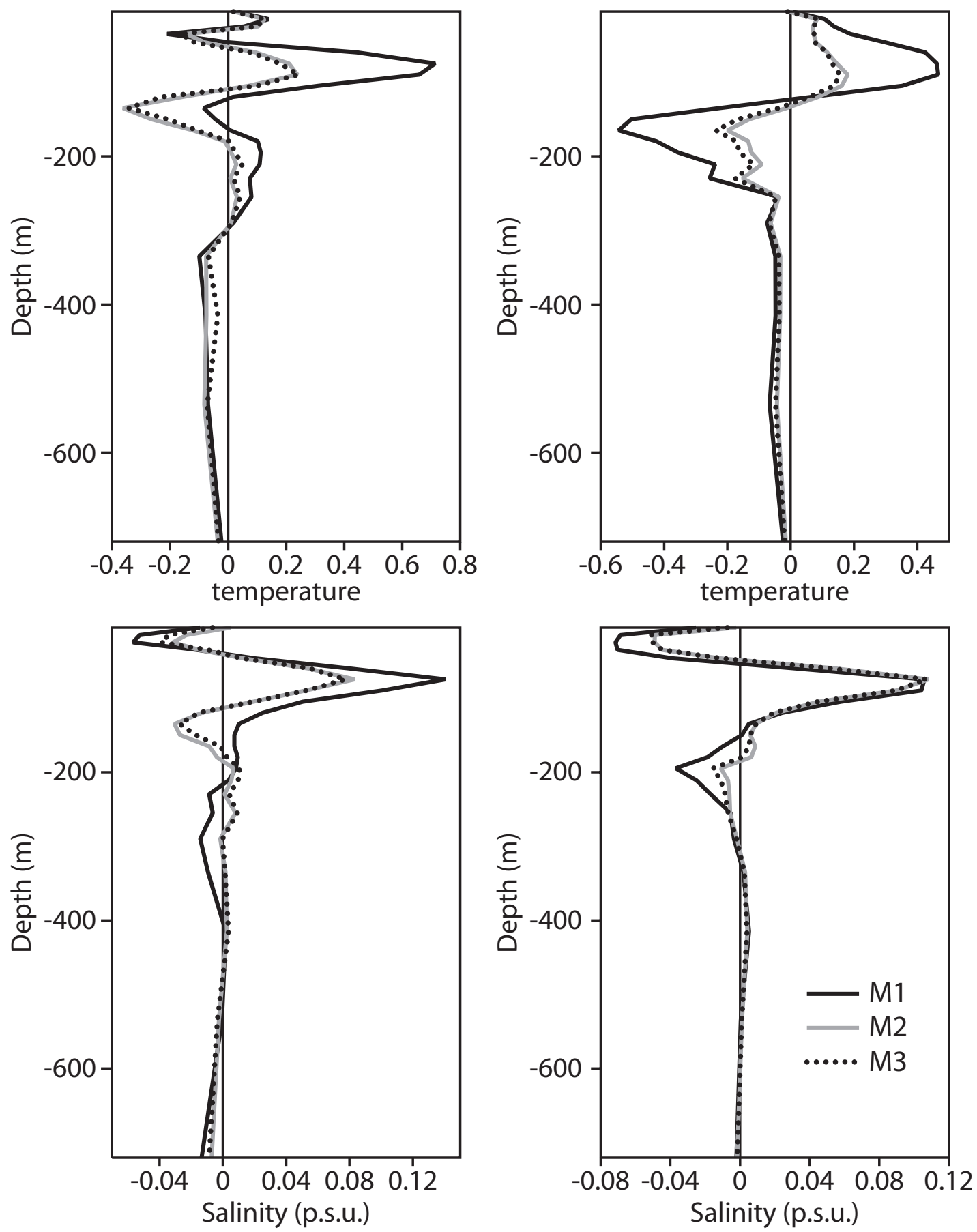

Fig. 1: Mean Analysis minus Observation over the equatorial Atlantic (left) and equatorial Pacific (right) for temperature (top) and salinity (bottom) for the three methods M1 (black), M2 (grey) and M3 (dotted). Averaging period is 2002-2003. 


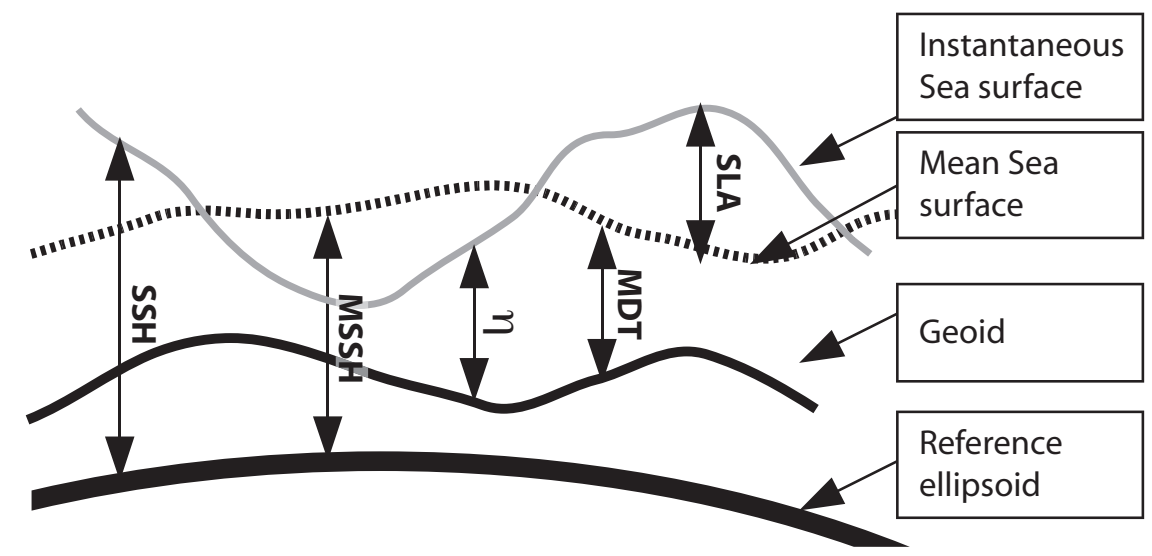

Fig. 2: Decomposition of Sea Surface Height 


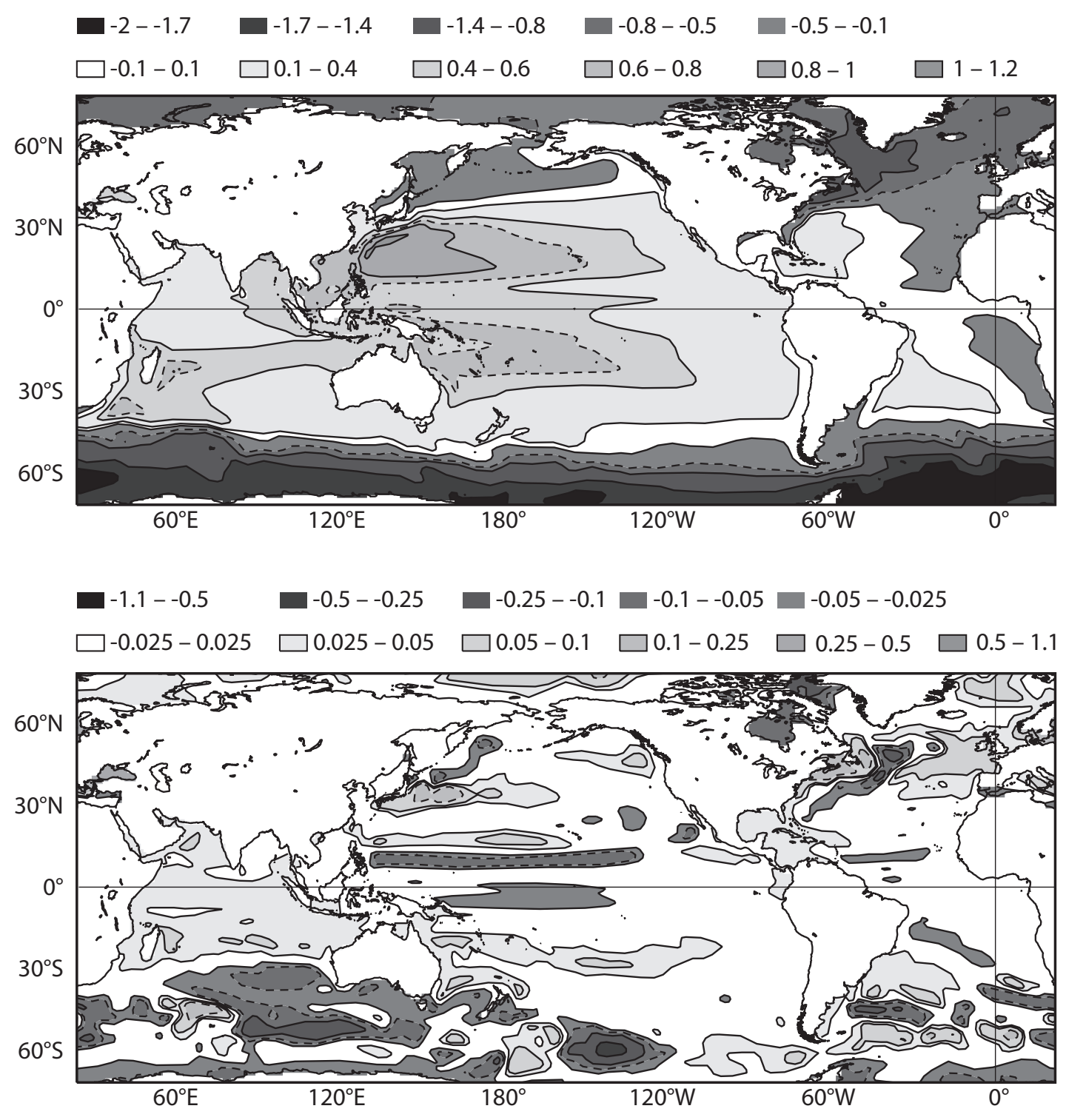

Fig. 3: Upper) MDT derived from 7 years of experiment E_TS (1993-1999); Lower) Difference in MDTs between E_TS and Control (no assimilation) for the same period. Units are metres. 

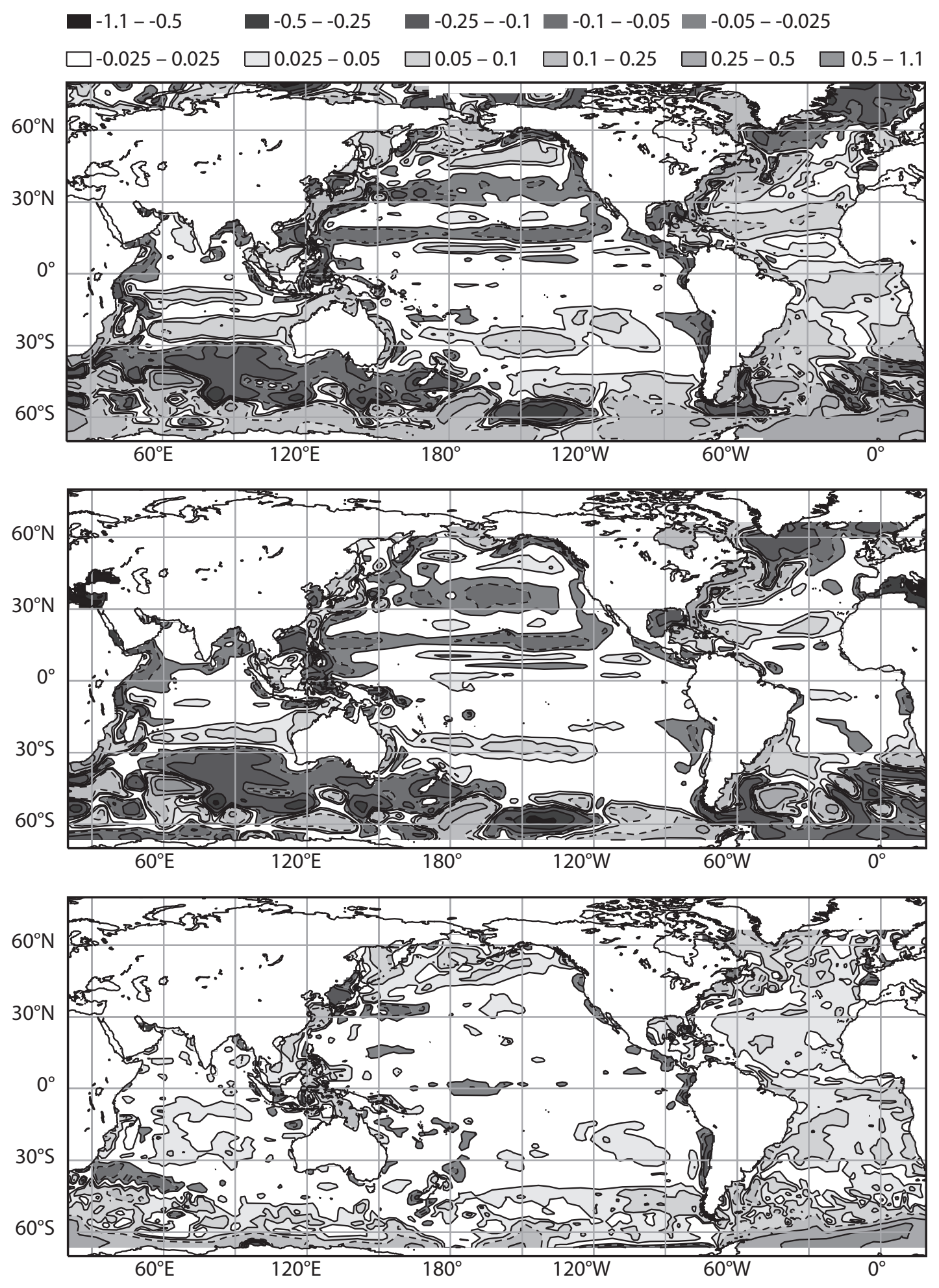

Fig. 4: Upper) Differences in Mean Dynamic Topography between Rio5 and an estimate from the ocean analysis from E_TS. Middle) Differences in Mean Dynamic Topography between Tap03 and an estimate from the ocean analysis from E_TS. Lower) Differences between Rio5 and Tap03. The global spatial average has been set to 0 for all fields. 

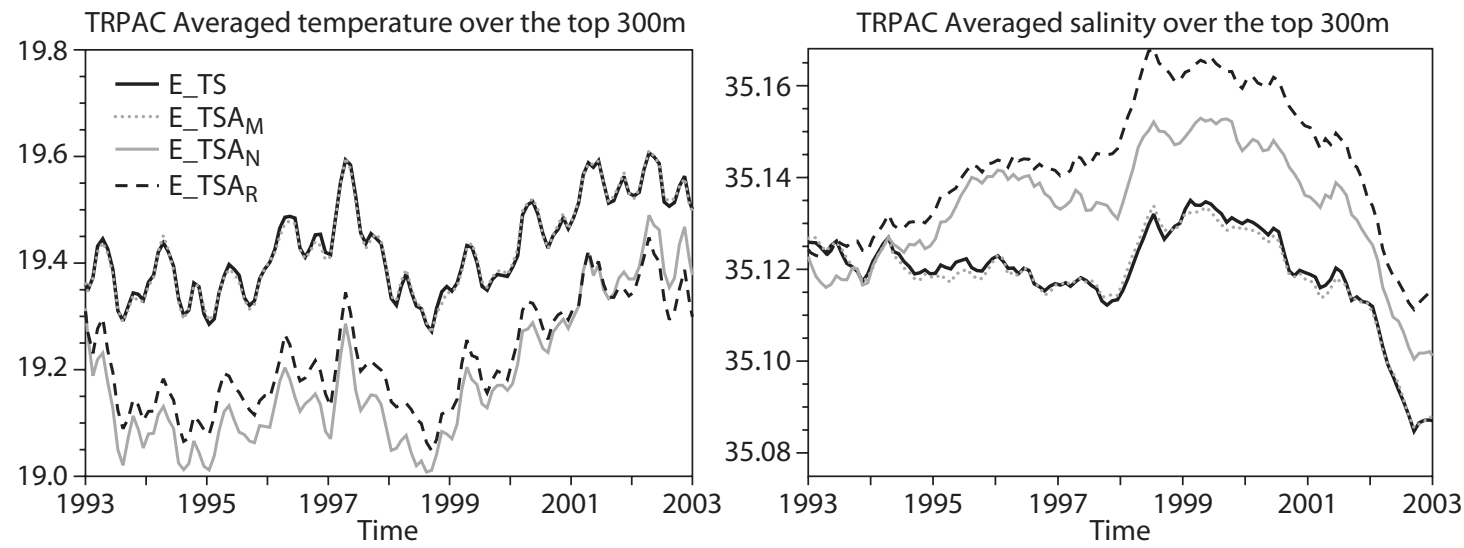

Fig. 5: Time series of temperatures (left) and salinity (right) averaged over the tropical Pacific ([30S, 30N]) and the first 300 meters of the expriments E_TS $A_{M}$ (dotted), E_TS $A_{N}$ (grey), E_TS $A_{R}$ (dashed) and E_TS (black). 

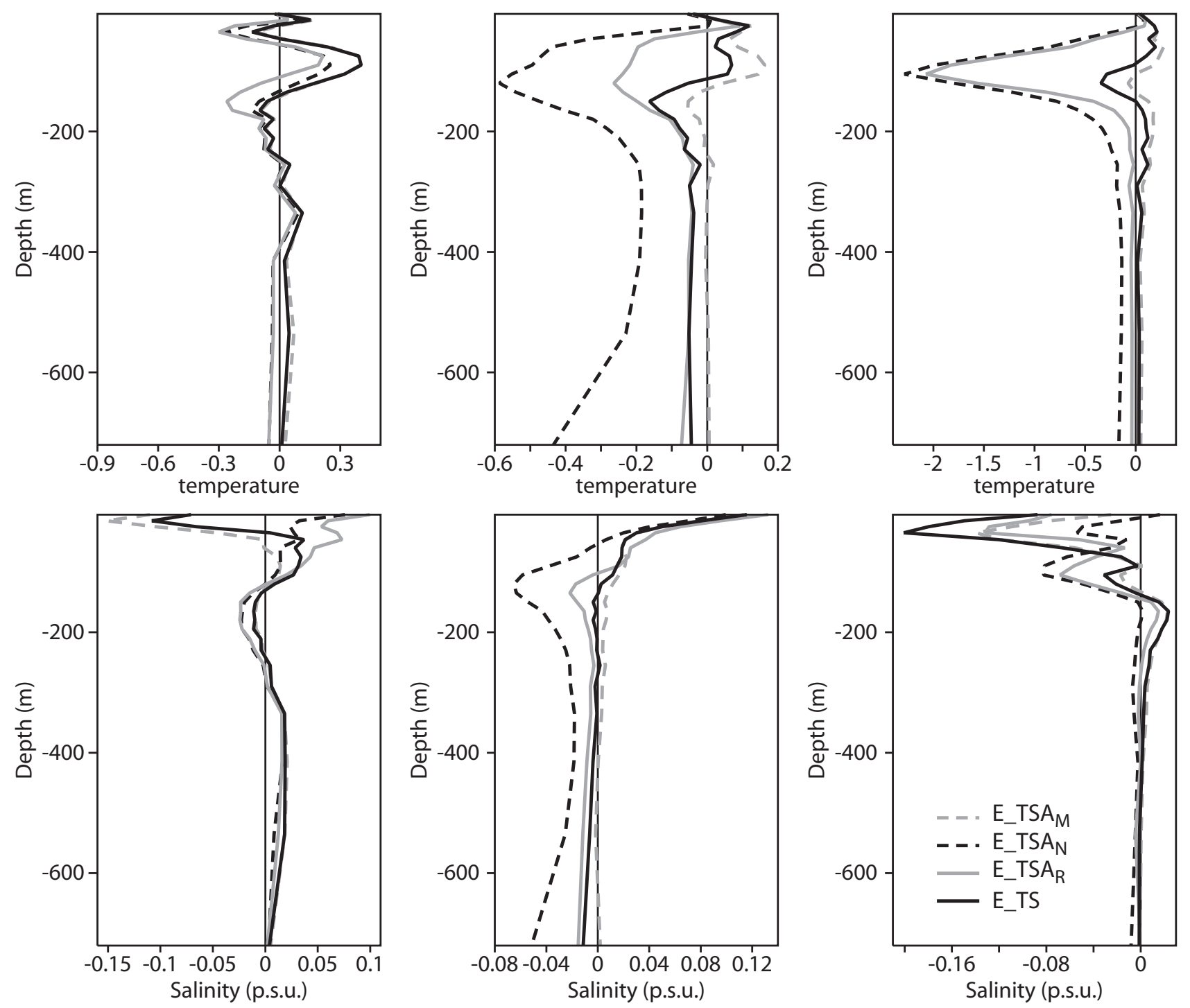

Fig. 6: Mean Analysis minus observation in the Nino3 [5S, 5N][210E, 270E], Tropical Atlantic $[20 \mathrm{~N}, 30 \mathrm{~N}]$ and Equatorial Indian $[5 \mathrm{~S}, 5 \mathrm{~N}]$, for temperature (top) and Salinity (bottom) of the expriments $E_{-} T S A_{M}$ (dashed gray), E_TS $A_{N}$ (dashed black), E_TSAR (grey) and E_TS (black). 


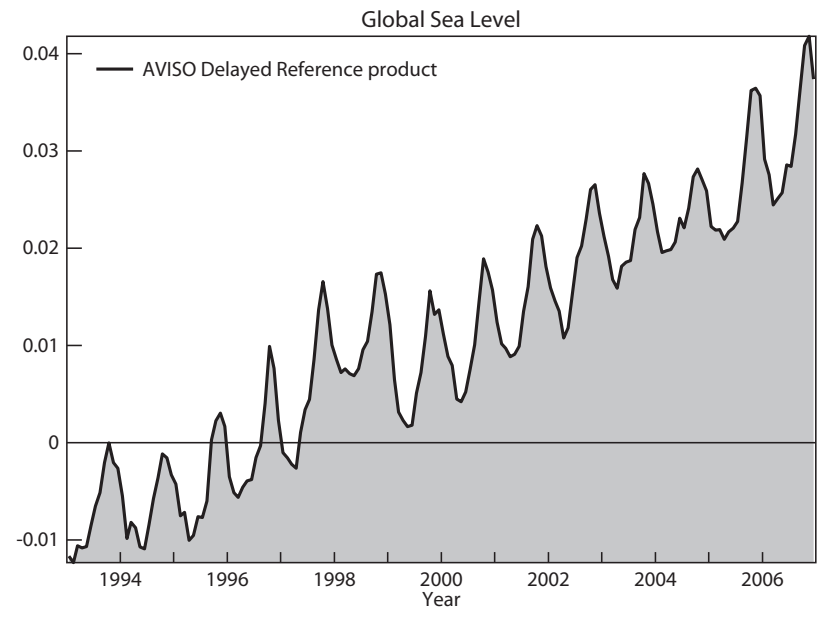

Fig. 7: Time series of the global sea level from altimeter data. Units are metres. From Balmaseda et al 2008. 


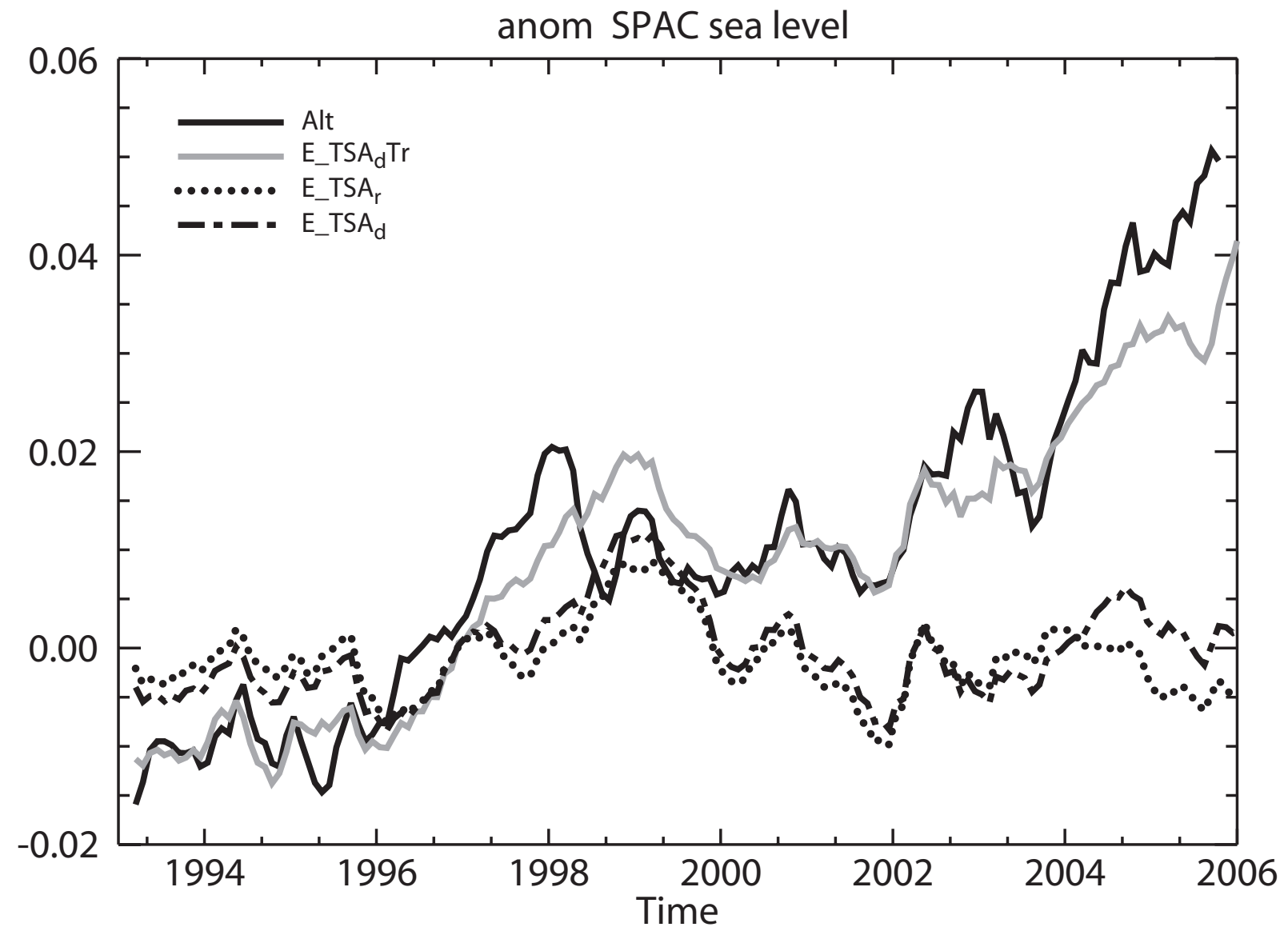

Fig. 8: Time-series of sea-level in the South Pacific for experiments E_TSAd, E_TS $A_{r}$ and $E_{-} T S A_{d} T r$ 


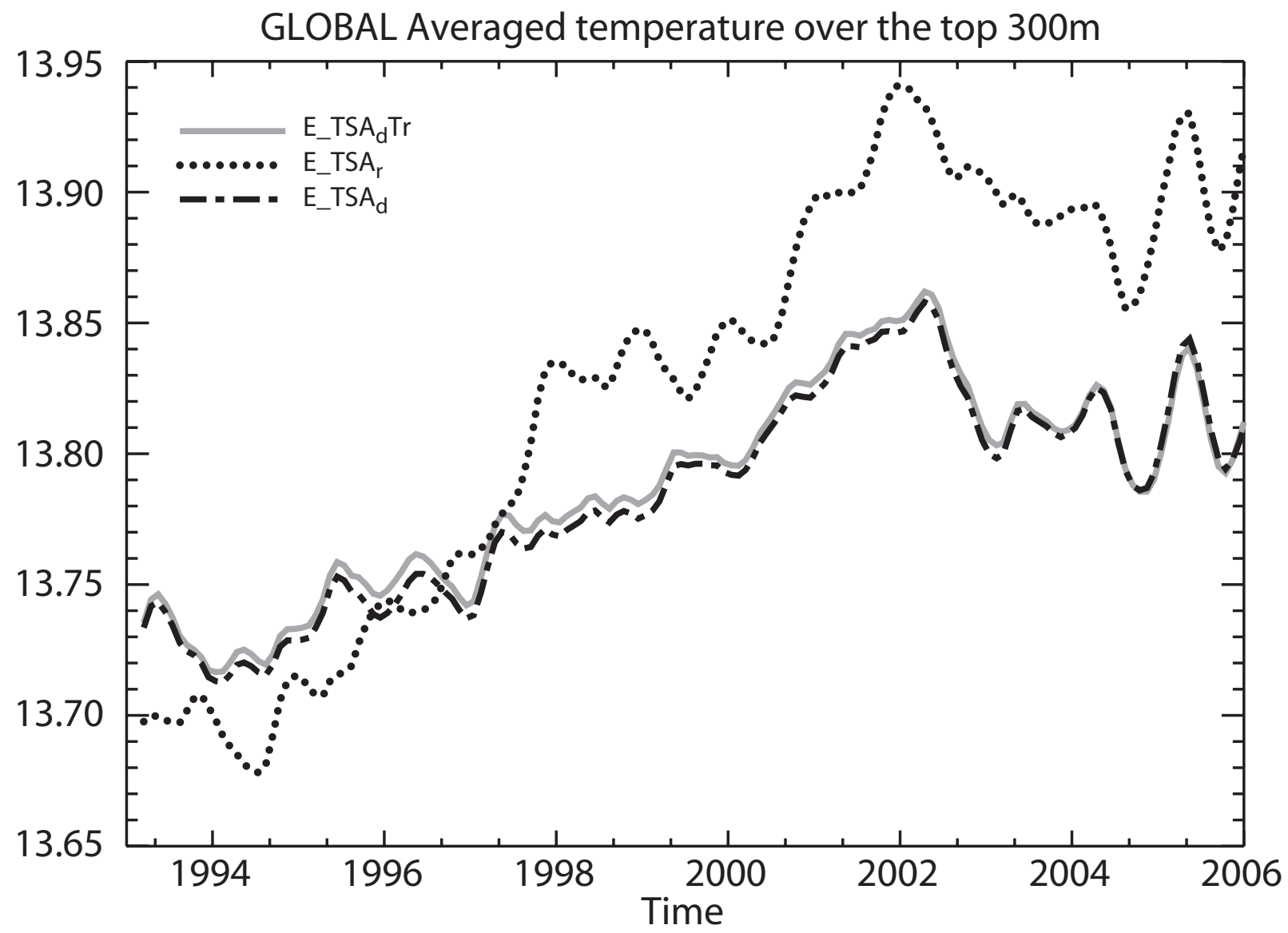

Fig. 9: Time-series of the global average of temperature over the first $300 \mathrm{~m}$ for experiments $E \_T S A_{d}, E \_T S A_{r}$ and $E \_T S A_{d} T r$ 

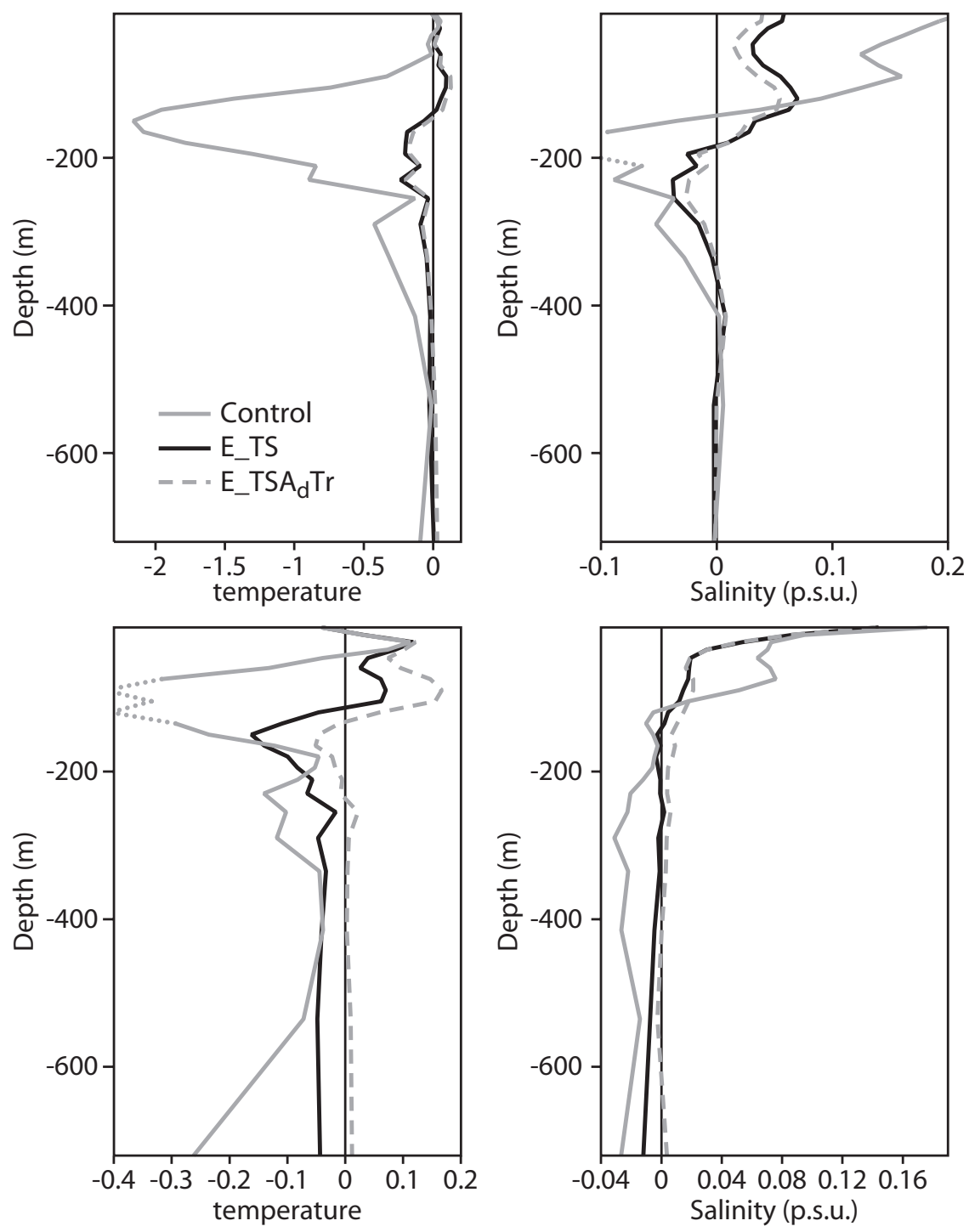

Fig. 10: Mean Analysis minus Observation averaged over the NINO4 (top) and Tropical Atlantic (bottom) regions for temperature (left) and salinity (right)for Control(grey), E_TS (black) and $E_{-} T S A_{d} \operatorname{Tr}$ (dashed grey) 

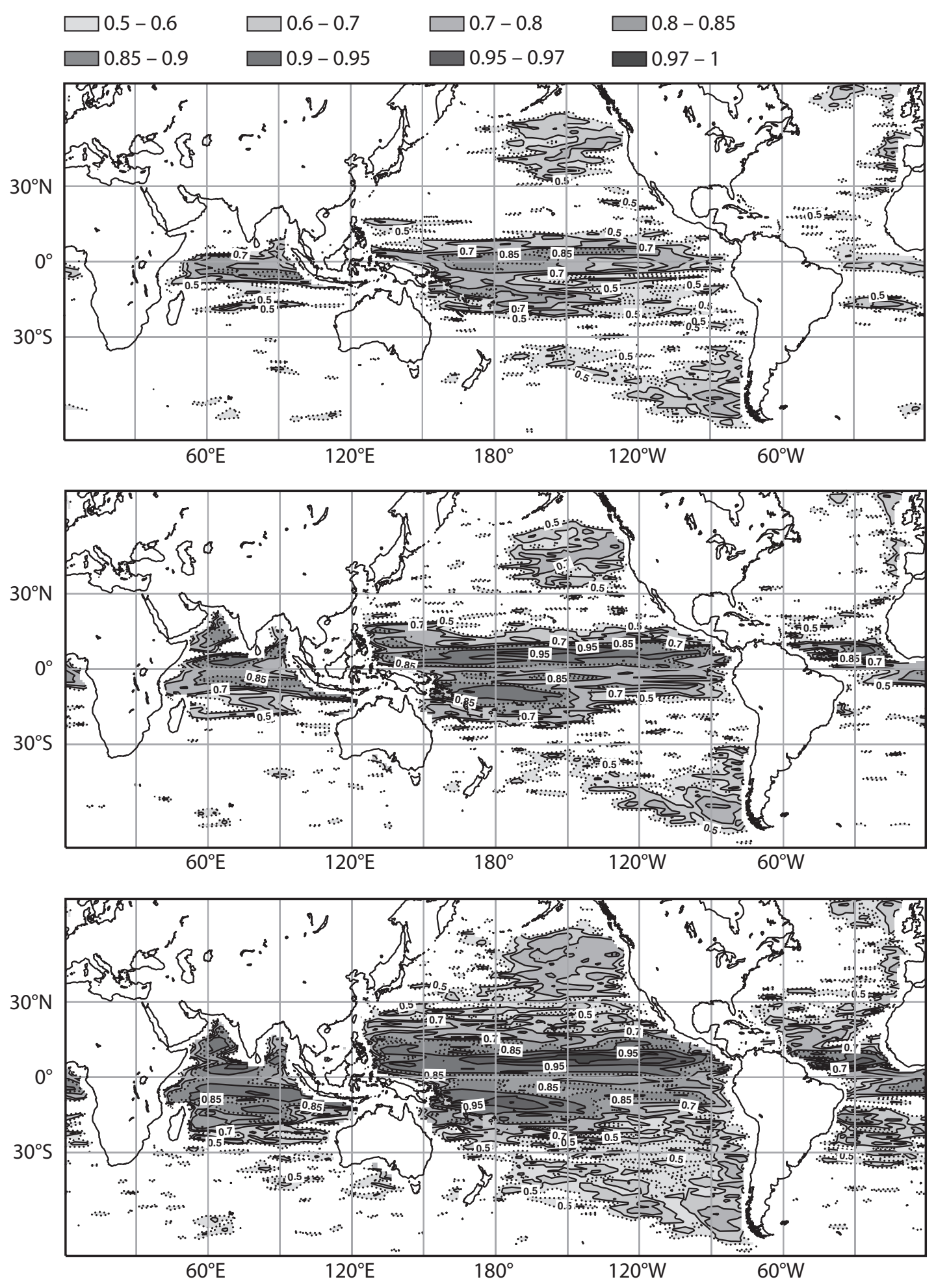

Fig. 11: Correlations with Oscar zonal component of the surface currents for Control(top), E_TS (middle) and E_TS $A_{d} \operatorname{Tr}$ (bottom) 

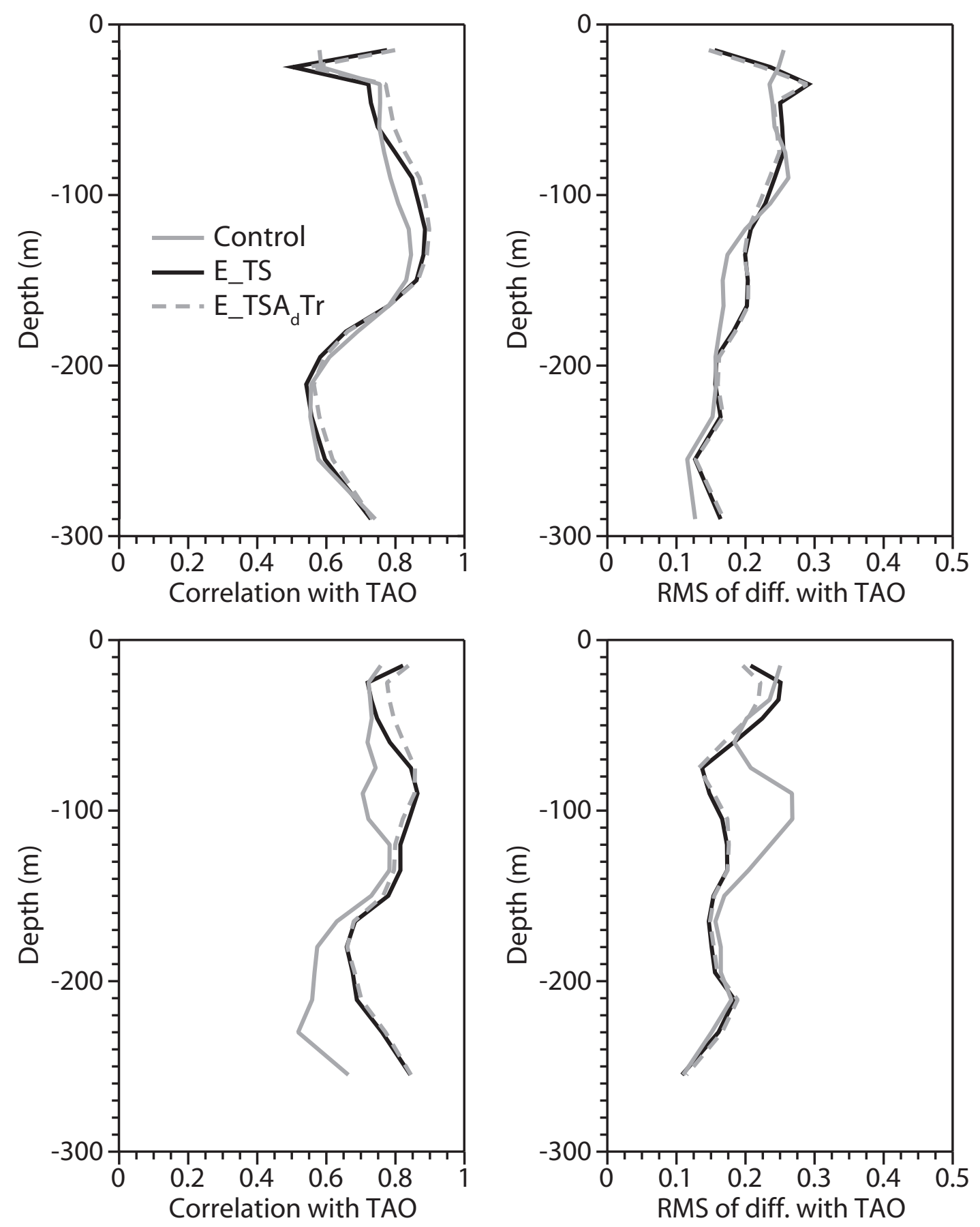

Fig. 12: Correlation (left) and RMS differences (right) with TAO currents at the equator at $170^{\circ} \mathrm{W}$ (top) and $156^{\circ} \mathrm{E}$ (bottom), for experiments Control, E_TS and E_TS $A_{d} T r$ 


\section{List of Tables}

1 Experiments to test sensitivity to MDT . . . . . . . . . . . . 38

2 Experiments to test sensitivity to trend. $E_{-} T S A_{d} T r$ is the same as $E \_T S A_{M}$ from Table 1 . . . . . . . . . . . . . . . . . . . . . 39

3 Experiments to test data impact, E_TS and E_TS $A_{d} T r$ are the same as in Table 2........................... 40 


\begin{tabular}{|l|l|l|}
\hline Experiment name & Altimeter anomalies used & MDT Used \\
\hline$E \_T S$ & No & - \\
$E \_T S A_{M}$ & Yes & Model, from E_TS \\
$E \_T S A_{R}$ & YES & Rio5 \\
$E \_T S A_{N}$ & YES & Nasa(Tap03) \\
\hline
\end{tabular}

Tab. 1: Experiments to test sensitivity to MDT 


\begin{tabular}{|l|l|l|l|}
\hline Experiment name & Altimeter anomalies used & Trend removed a priori & Trend added a posteriori \\
\hline$E \_T S$ & No & - & - \\
$E \_T S A_{d}$ & Yes & Yes & No \\
$E \_T S A_{r}$ & Yes & No & No \\
$E \_T S A_{d} T r$ & Yes & Yes & Yes \\
\hline
\end{tabular}

Tab. 2: Experiments to test sensitivity to trend. E_TSA $A_{d} T r$ is the same as $E_{-} T S A_{M}$ from Table 1 


\begin{tabular}{|l|l|l|}
\hline Experiment name & Altimeter anomalies used & In situ data used \\
\hline Control & No & No \\
$E \_T S$ & No & Yes \\
$E \_T S A_{d} T r$ & Yes & Yes \\
\hline
\end{tabular}

Tab. 3: Experiments to test data impact, E_TS and $E_{-} T S A_{d} T r$ are the same as in Table 2 